\title{
Materiality, New Economics and Dynamics in Controlled Cultural Writing: A Derridean Exploration
}

\author{
Chung-ling Shih \\ English Department, National Kaohsiung First University of Science and Technology, Taiwan
}

\begin{abstract}
Advanced information technologies have triggered a return to materialism with a focus on rapid re/production of cultural resources in multimedia applications. Machine-enabled translation has emerged as one possible solution to achieving the goal of massive re/production and transmission of cultural materials in diverse languages for international cross-cultural communication on the web. In light of the need of improving machine translation (MT) performance, controlled cultural writing (CCW) is here proposed as an alternative to general language writing. CCW refigures the format and re-presents the utterances of cultural texts emphasizing material presence of factual information for easy machine rendition. In addition to its materialistic feature, $\mathrm{CCW}$ undergoes a dramatic modification through paraphrase so that its meaning or thematic message is far from matching the original one. This dynamic feature is justified by the Derridean concepts of dissemination and difference. One more feature of $\mathrm{CCW}$ is its function of new economics resulting from its economical way of reproducing cultural information through multilingual MT application. Drawing on the controlled writings of Chinese folk texts as a case study, this paper explores the three attributes of CCW by using Derridean deconstruction concepts as the theoretical framework.
\end{abstract}

Index Terms - CCW, MT application, new economics, materiality, dynamics, Derridean deconstruction concepts

\section{INTRODUCTION}

The western industrial revolution transformed the way of producing art and stimulated the turn to cultural materialism. The high/minority culture of literature, music, and art, created by a small group of literary figures and artists, gave way to the massive/majority culture reproduced by the machine (Williams 1958/1982). Today, advanced information technologies trigger a return to cultural materialism through the re/production of cultural sources in multimedia applications. One of the information technologies is online machine translation (MT) tool that helps render the cultural information into multiple languages within a short time. However, the semantic clarity, grammatical accuracy and pragmatic appropriateness of the MT output needs to be improved by controlling the source text. For this reason, controlled cultural writing $(\mathrm{CCW})$ is proposed to improve the MT performance. CL refigures the format and re-presents cultural experiences emphasizing their material presence for easy machine rendition. Removal of local traits, appealing touch, aesthetic sense, along with the suppression of exotic aura and genuine/bodily experiences in CL writing, supports Derrida's $(1973,1976,1978,1981,1982)$ concepts of disrupted, de-centered writing.

In addition, CCW has shown a new economics since it leads to cultural re/production and massive consumption on the web through the multilingual MT application in a cost-effective way. Finally, CCW has to paraphrase all the cultural references so it loses its origin and authenticity in the re/de-presentations. This point concurs with the Derridean concepts of dissemination and difference. Above all, CCW reveals the features of materiality, new economics and dynamics. Drawing on Taiwan's controlled writings of Chinese folk texts as a case study, this paper explores the three attributes of $\mathrm{CCW}$ by using Derridean deconstruction concepts as the theoretical framework. For investigation, three research questions are raised as follows.

1) How does CCW present the materialistic feature using cultural references as examples?

2) How does CCW account for a new economics of cultural re-production and consumption on the web?

3) How does CCW take on the significance of disseminative/diffuse meanings in its textual creation and multilingual MT application?

In seeking answers to these questions, this paper tries to testify to the materiality, production economics, and disseminative meanings of CCW that is designed for effective MT application. The economic, organic, dynamic, unstable, incomplete re/de-presentations of $\mathrm{CCW}$ would be discussed within the theoretical framework of Derridean notions of de-authorization, dissemination and difference.

\section{Controlled Language and Machine Translation}

Before a discussion on the materiality and new economics of $\mathrm{CCW}$, there is a need to introduce controlled language (CL) and machine translation. CL can be viewed as an artificial language because it restricts its range in vocabulary and 
sentence structure. ${ }^{1}$ The words with multiple meanings and complicated sentence structures are avoided and the sentence length is averagely less than 25 words. Ideally, CL follows the rule of "one word, one meaning" and "one sentence, one idea". More importantly, semantically unclear expressions such as idioms, slang and cultural references should be replaced with common, easily-understood words. Thus, CCW is suitable for the MT system to create multilingual translations.

With regard to the MT system, the Chinese-to-English rendition by the statistics-based MT system, e.g., Google Translate (developed by Google Company), is generally better than that created by the traditional rule-based MT system, e.g., TransWhiz (developed by Taiwan's Otek Company), ${ }^{2}$ in terms of semantic clarity and grammatical accuracy. In this paper, Google Translate is used to create all multilingual translations. However, whatever MT tools are, the shorter the source text is, the better MT output is created. Furthermore, it is found that the simpler lexicon and syntax of the source text, the more comprehensible of the MT output. In other words, when linguistic signs or segments embody clear and definite meanings, they are easier to be parsed, transferred and rendered by the MT system. ${ }^{3}$ However, we must notice that the MT performance varies as different presentations are used in the CCW. Furthermore, the expanding size of the MT corpuses affects the quality of the MT output.

\section{DERRIDEAN DECONSTRUCTION CONCEPTS}

Since this paper used Derridean concepts as the theoretical framework to support analytical arguments with, some basic concepts of Derrida's theory would be introduced in this section. Derrida's arguments aim to challenge the concept of origin or the so-called logos and truth. Once when reality is linguistically formulated through words, its meaning becomes indecisive and de-centered. From Derrida's perspective, meaning is not something pre-existing in the mind that we can fetch and express it out. This notion opposes the neo-classical metaphysical concepts that meanings of words/language are derived from deep grammar (Chomsky) or social schema (Wittgenstein) or others. Derrida saw these analytical viewpoints as too narrow and self-centered. Derrida (1976) devalued structuralism as a devoted commitment to an unproblematic ontology that adheres to the "self-deceptive assumption of Western reason" and to "the original source of reality [that] could be recovered in its full integrity" (qtd. in Boyne, 1990, p. 106). For Derrida, an understanding of a word depends on other words or socio-cultural conventions, not on the meaning of the word per se. Meaning in a text/writing results from the reader's interpreting, so it is shifting and individual. This point outlines Derrida's concept of différance.

The French word différance means both defer and differ, carrying the connotation of breaching in writing. It suggests that each piece of writing creates some rupture or separation from external reality because language cannot fully present the author's interpretation of reality and thinking. Furthermore, writing records trace and this trace cannot lead back to the origin. As Derrida (1973) has put it, "Trace, as memory, is not pure breaching that might be re-appropriated at any time as simple presence. It is rather the ungraspable and indivisible difference between breaches" (p. 150). Overtly there is no return to an origin and only the recurring circulation of copies with some difference from the origin. Derrida challenged western rationality/reason that was used to seek one-to-one correspondence between signifier and signified. For Derrida, this correspondence was impossible because it had been totally disrupted. Similarly, the present research emphasizes that there is no exact match between CCW and GCW. Each CCW records the previous cultural traces, but the traces through lexical, syntactic and contextual adaptations cannot lead us back to the origin.

Simply put, Derrida's views revolve around breaching and dissemination of meaning in writing. Derrida agreed that the state of language was dissemination, a state of unfulfilled meanings within the absence of all signified (qtd. in Scott, 2002). The creation of multiple meanings depends on the reader's interpretations. As Scott looked at this deconstruction symptom of de-centralization, the removal of the fixed signified and the abolishment of the subjectivity of the author/writer released the dynamic energy of language and unleashes its creativity. Today, in the technological world, faithful reference to the origin is impossible in the post/Derridean sense. All cultural products, which come up under massive reproduction with the help of various multimedia and information technologies, have demonstrated some difference from the original ones. This case holds true with CCW as it is open to varied ways of adaptation and/or control, and thus gives its cultural presentation diverse forms.

\section{Materiality OF CCW}

In response to the first research question, analysis of $\mathrm{CCW}$ leads to a finding that its cultural presentation was heavily materialistic because it used objective, factual discourses, not subjective, metaphorical ones. If creative writing emphasizes aesthetic appreciation through the use of some rhetorical devices, CCW focuses on effective communication relying on clear, plain wording and informative presentations. CCW and its machine translation send readers to a remote place where the original emotional or bodily experiences cannot be felt and where only cultural facts can be acquired. In CCW, the distance from the local culture is inevitably created because the primitive, exotic and folk elements that create an aesthetic taste and emotional touch must be removed. All the narratives or utterances that can evoke the readers' imagination, aspiration, inspiration, desire and curiosity must be suppressed as they hinder the appropriate rendition of the machine. The following examples, extracted from some cultural texts of online Encyclopedia of Taiwan and adapted by the author, may illustrate the materiality feature of CCW. ST means the source 
text.

Ex. 1 Extracted from "Ku hao-ming” [lit: Crying for good life] (Xin, 2009)

ST: 新娘哭泣是表示對娘家一種依依不捨的情懷。

[lit: Bride crying is presenting to her natal family a kind of emotional attachment]

$\mathrm{CCW}$ : 新娘會哭泣因爲她不願意離開她自己的家。

[lit: Bride will cry because she does not want leave her own family.]

MT: The bride will cry because she does not want to leave her own home.

After removing the metaphorical description "emotional attachment", Google Translate produced an understandable translation. Another example is given below.

Ex. 2 Extracted from “Ku hao-ming” [lit: Crying for good life] (Xin, 2009)

ST: 據說新娘哭得越大聲, 未來的生活也就越幸福, 並且也越旺娘家方面的運勢。

[lit: It is said bride cries louder, the future life would be happier, and also more prosper her natal family.]

$\mathrm{CCW}$ ：臺灣人相信：當新娘哭得越大聲，她的生活會是更幸福，且她的娘家也會變得更幸運。

[lit: Taiwanese believe: when bride cries louder, her life would be happier, and her natal family would become luckier.]

MT: Taiwanese believe: When the bride cried louder, her life will be happier, and her family will become even more fortunate.

In the example above, the original audio metaphor, "the loud crying that prospers her own family" was adapted with a common account "her own family would become more fortunate" in the CCW. In short, all articulations were converted to factual reporting or explanatory discourses that presented referential meanings, not connotative meanings. CCW became heavily materialistic, characterized by simplified narratives and substantial, factual information. Its semantic clarity and pragmatic appropriateness led to good-quality, understandable MT outputs.

\section{ECONOMICS OF CULTURAL PRODUCTION AND CONSUMPTION}

In response to the second research question, $\mathrm{CCW}$ and online MT application have demonstrated a new economics of cultural production and consumption on the web. CCW helped improve the performance of multilingual machine translations, and the online cultural re-production allowed for global information exchange across the borders of different countries. This relationship between massive cultural re/production and consumption can be explored from the post/Derridean or post/deconstruction perspective.

As opposed to Derrida, Frankfurt school associates, such as Adorno (1991, 1994) and Adorno \& Horkheimer (1997), condemned the technological forces for destroying noble, unique attributes of arts and cultural goods. However, Derrida held a view that because mass-produced cultural goods were secularized and commercialized so that the majority of people could afford it. In this paper, Shih argued that although de-individualization led to the loss of aura and origin, it has led the text/works into a new zone where more people could enjoy, approach and know it. When a controlled cultural text is popularized through MT-driven repetitive production, it benefits many people who can access and acquire the cultural information in their native languages.

The cultural re-production resulting from CCW and MT applications can be viewed as liberating culture from the minority group's privileged possession and enjoyment (monopolization). Examining the CCW from the post/Derridean or anti-Adorno perspective, we can argue that $\mathrm{CCW}$ has enlarged its scope of service and contributes to the realization of the ideal of cultural humanism without discrimination against non-privileged English audiences. In spite of the negative accusations of the secularization and de-individualization of cultural texts, CCW and online MT application have provided international audiences with an easy, convenient access to cultural information on the web.

Actually, as massive cultural production is criticized as "a business enterprise operated for profit" (Adorno, 1984, p. 26), we cannot overlook that transforming art and culture from the indispensable image to a commodity for free trade is an irresistible trend under the mantle of globalization. Out of the need of reducing international conflicts and increasing the understanding of other cultures, a new economics has been formed and more people are eager to enjoy all culture goods either domestically or abroad. This phenomenon demonstrates a mixture of high and low art/cultures. The conventional, hierarchical from of cultural economics is declining because its enclosed economic system does not consider the needs of the powerless and marginalized groups. Rather, when CCW is offered on the web, Google Translate immediately translates it into 66 languages, and the multiple MT outputs are readable and comprehensible to native target language audiences. When the goal of massive consumption of cultural resources is fulfilled, CCW has successfully justified the function of the new economics based on the effective MT application.

\section{Disseminative/DifFusing MEANINGS}

In response to the third research question, $\mathrm{CCW}$ has taken on some significance of disseminative and diffusing meanings from the perspective of Derridean concepts. The absence of fixed meaning and changing styles of presentation can be examined by using some examples retrieved from controlled cultural texts. It is noted that to improve MT performance, the editors/writers of CCW cannot preserve original primitive idioms and metaphorical expressions. The idiomatic expression of "Chuang mu" [lit: Bed Mother], for example, must be adapted as "Chuang 
nushen" [lit: Bed Goddess], and then the original image of merciful, care-taking mother was lost. Although Goddess can bless the sleeping babies, she might not be as kind and gentle as a mother. Furthermore, when the cultural reference "Ming hun" [lit: ghost marriage] was edited as "Jingshen hunyin" [lit: spiritual marriage] for the western audience, the original meaning of "marrying a dead girl" was not clearly re-presented, not to mention its hidden socio-cultural implications. ${ }^{4}$ Adaptation incurs some breaching and disruption, concurring with Derrida's anti-Totalitarianism notion that there is often a gap between true meaning and verbal re-presentation.

The writers of CCW play a crucial role in communicating the cultural message to international audiences, and different versions of CCW lead to different MT outputs. Regarding the cultural reference "Dailu ji" [lit: leading-way chicken], the MT of the controlled expression, "Yīduì jī yǐ dàigěi xīnhūn fūfù xìngfú" [lit: a pair of chicken to bring the newly-wed couple happiness] is One pair of chicken to bring the newlyweds happiness, but the MT of another controlled expression, "Yīduì jī yònglái qìngzhù yīgè xīnjiā de chénglì zài jiéhūn zhīhòu" [lit: a pair of chicken used to celebrate a new home's establishment after marriage] is One pair of chicken used to celebrate the establishment of a new home after marriage. The former CCW suggests that the pair of chicken is a gift for wedding happiness, and the latter, a symbol of building a new family after marriage. The two different ways of presenting the same reference in $\mathrm{CCW}$, due to the editors/writers' different interpretations, create different MT outputs and convey different messages. One more example is given below.

Ex. 3 Extracted from "Huan du" [lit: Changing the belly] (Wei, 2009)

$\underline{\mathrm{ST}}$ : 人們認爲吃猪肚即可以換肚。[lit: People think eating pig belly just can change belly.]

CCW 1：當已婚婦女吃豬肚，他們很容易地懷孕。猪肚子是象徵著生育。

[lit: When married women eat pig belly, they are very likely pregnant. Pig belly is a symbol of birth.]

MT1: When married women eat pig stomach, they easily become pregnant. Pig stomach is a symbol of fertility.

CCW 2: 人們認爲假如已婚婦女吃了豬肚，她們可以懷孕。這是一種吉祥的象徵。

[lit: People thought that if married women eat pig belly, they may be pregnant. This is a symbol of good luck.]

MT 2: People think that if married women eat tripe, they may be pregnant. This is a symbol of good fortune.

In the example above, CCW1/MT1 emphasizes the cause-effect relationship between eating pig belly and pregnancy. In contrast, CCW2/MT2 tries to send a message that eating pig belly helps married women to be pregnant so that it is viewed as an emblem of good luck. We also note that the same CCW translated by Good Translate in 2012 and in 2013 are slightly different. As the size and corpus of Google Translate in 2013 has changed, its MT output surely shows some differences. One example is presented below.

Ex. 4 Extracted from "Zha Handanye" [lit: Bombing Lord Handan] (Wu, 2009)

CCW: Bombing Lord Handan 是一個習俗, 在元商節, 在臺東。漢人相信 : 寒單爺是一位相當重要的神祇, 在 台東地區。根據一傳說, 寒單爺是害怕冷天氣。因此, 當他正是在出巡, 一些信徒點燃鞭炮爲他驅寒。他將會 出巡, 長達兩天, 在每年元䆚節。這是一個重要活動, 在台東。

MT1: Bombing Lord Handan is a custom in the Lantern Festival in Taitung. Han Chinese believe: Han Dan is a very important deity in the Taitung area. According to a legend, the Han Dan is afraid of cold weather. Therefore, when he is in the parade, some believers lit firecrackers for him to fend off the cold. He will be touring up to two days, in the annual Lantern Festival. This is an important activity in Taitung. (created in 2012)

MT2: Bombing Lord Handan is a custom in the Lantern Festival in Taitung. Han Chinese believe: Han Dan is a very important deity in the Taitung area. According to a legend, the Han Dan is afraid of cold weather. Therefore, when he is in parade, some believers lit firecrackers for him to fend off the cold. He will be on parade, up to two days, in the annual Lantern Festival. This is an important activity in Taitung. (created in 2013)

The marked portions indicate some differences in the English machine translations between 2012 and 2013. This variation denotes that the MT system does not have a steady performance because the statistical result of the most frequent occurrence for each segment is different at different times and then the stringing up of the segments together create different translations. MT application suggests that viewed from the theoretical perspective of Derridean concepts, the machine-created translation can be permanently deferred and different as its corpus size and contents undergo constant changes.

In short, different $\mathrm{CCW}$ writers present the same cultural reference or message with different syntax, wording and expressions depending on their interpretations. The same CCW probably creates different English machine translations at different times. The loss of control in translation can be analogous to Derrida's (1973) argument that language is "the structure peculiar to language alone, which allows it to function entirely by itself when its intention is cut off from intuition...." (p. 92). CCW, once submitted to the MT system, only allows it to function by itself. In this respect, the editor/writer's intention in CCW can only be retained or/and represented in the MT output at one moment, but not at another. The writer's intention in CCW is tentatively traceable, and the meaning is only tentatively fixed.

\section{CONCLUDING REMARKS}

This paper identifies a changing scenario in culture re-production and consumption using CCW and MT application as a case study. CCW refigures the format and re-presents the utterances of cultural texts to emphasize the material presence of factual information for easy machine rendition, fully supporting Derrida's disrupted, de-centered approach 
to writing. CCW suggests economical materialism by reducing idiomatic or metaphorical presentations to referential meanings for effective MT application. Production economics, textual materiality and disseminative meanings in CCW denote a need to re-examine intercultural communication from the Derridean perspective under the push of globalization.

One might well ask if CCW for MT-driven intercultural communication is a blessing or a curse. From the functional point of view, improved MT quality through CCW increases an exchange of cultural information across borders of countries. Secularized and simplified cultural writing fits multilingual machine translations and thus provides an easy, convenient access to many international readers. However, CCW is simultaneously accused of creating some alienation from the cultural origin, and its MT application distorts, to some extents, original meanings at the cost of re/de-presentation. Thus, a paradox stays with $\mathrm{CCW}$--destroying the source culture at one place, but rejuvenating it in a new form/language at other places.

Notes

1. To create multilingual translations of product instructions and user's manuals, controlled English (CE) has been used in western large-scale companies and the localization industry for business profits.

2. The translation through the application of a statistics/corpus-based MT system is more natural and more comprehensible. The rule-based MT system creates a translation through three phases such as analysis, transfer and generation, and its output tends to be a word-for-word translation (Shih, 2006). In contrast, the statistics/corpus-based MT system considers various candidate translations and selects the statistically most likely option for the translation (Coffey, n.d.).

3. The MT tool has no common sense to judge the meaning of words based on the context and has no power to create a new translation out of nothing, so the use of common words that have been saved in the corpus of an MT system tends to create a good-quality machine translation.

4. It is noted that in ancient Taiwan, a dead girl's memorial tablet could not be put in her own family's shrine, so her parents had to find a man to marry her so that her memorial tablet could be kept in her husband's family shrine. This cultural practice might be ridiculed by people outside of Taiwan, and thereby the original presentation is adapted.

\section{ACKNOWLEDGEMENT}

The author thanks Taiwan's NSC for the funding grant, so she can complete the research and write the findings into the paper published in this journal.

\section{REFERENCES}

[1] Adorno, T.W. (1984). Aesthetic theory. C. Lenhardt (Trans.). London: Routledge and Kegan Paul.

[2] Adorno, T.W. (1991). The culture industry. London: Routledge.

[3] Adorno, T.W. (1994). The stars down to earth and other essays on the irrational in culture. London: Routledge.

[4] Adorno, T.W. \& Horkheimer, M. (1997). Dialectic of enlightenment. Verso: London.

[5] Boyne, R. (1990). Foucault and Derrida, The other side of reason. London: Unwin Hyman.

[6] Coffey, N. (n.d.). Machine translation-How it works, what users expect and what they get. Retrieved May 2, 2012 from http://EzineArticles.com/?expert=Neil_Coffey.

[7] Derrida, J. (1976). Of grammatology. Baltimore, Md.: Johns Hopkins University Press.

[8] Derrida, J. (1973). Speech and phenomena and other essays on Husserl's theory of signs. Northwestern University Press.

[9] Derrida, J. (1982). Margins of philosophy. Chicago: The University of Chicago Press.

[10] Derrida, J. (1978). Writing and difference. London: Routledge.

[11] Derrida, J. (1981). Dissemination. London: Athlone Press.

[12] Scott, A. (2002). Derrida-Of grammatology. $\quad$ Retrieved June $21, \quad 2012$ from http://www.angelfire.com/md2.timewarp/derrida.html.

[13] Shih, C.-L. (2006). Helpful assistance to translators: MT and TM. Taipei, Taiwan: Bookman Books, Ltd.

[14] Wei, X.-Y. (2009). Changing the belly. Retrieved March 3, 2012 from http://taiwanpedia.culture.tw/web/content?ID=11538\&Keyword=\%E6\%8F\%9B\%E8\% 82\%9A.

[15] Williams, R. (1958/1982). Culture and society. London: The Hogarth Press.

[16] Wu, P.-Q. (2009). Bombing Lord Handan. Retrieved March 2, 2012 from http://taiwanpedia.culture.tw/web/content?ID=11673\&Keyword=\%E7\%82\%B8\%E5\%AF\%92\%E5\%96\%AE.

[17] Xin, Y.-P. (2009). Crying for good life. Retrieved March 2, 2012 from Encyclopedia of Taiwan. Retrieved from http://taiwanpedia.culture.tw/web/content?ID=114637\%AF\%E9\%9B\%9E.

Chung-ling Shih, English Professor, is now teaching at the English Department of National Kaohsiung First University of Science and Technology, Taiwan. She received a Ph. D. in British and American Literature from National Taiwan Normal University in 1998. However, her major interest and current researches have shifted from literature to translation studies. Her study focus is particularly on training and research in MT, TM, CTS, cultural studies, translation theories and relevant others. She was grateful to Taiwan's NSC for granting her funding to complete a series of researches and part of the results was posted on her teaching website. Her research results can be found in some books such as Helpful Assistance to Translators: MT \& TM (2006), Real-time 
Communication through Machine-enabled Translation: Taiwan's Oracle Poetry (2011), Translation Research Models and Application (2012) and others. Over 30 papers in her name were published in various journals in Taiwan and abroad. 